\title{
WEB-BASED DATA MINING TOOLS : PERFORMING FEEDBACK ANALYSIS AND ASSOCIATION RULE MINING
}

\author{
Pratiyush Guleria ${ }^{1}$, Akshay Sharma ${ }^{2}$, Manu Sood $^{1}$ \\ ${ }^{1}$ Department of Computer Science, \\ Himachal Pradesh University, Shimla, H.P, India \\ ${ }^{2}$ Department of Computer Science, \\ National Institute of Technology, Hamirpur, H.P, India
}

\begin{abstract}
This paper aims to explain the web-enabled tools for educational data mining. The proposed web-based tool developed using Asp.Net framework and php can be helpful for universities or institutions providing the students with elective courses as well improving academic activities based on feedback collected from students. In Asp.Net tool, association rule mining using Apriori algorithm is used whereas in php based Feedback Analytical Tool, feedback related to faculty and institutional infrastructure is collected from students and based on that Feedback it shows performance of faculty and institution. Using that data, it helps management to improve in-house training skills and gains knowledge about educational trends which is to be followed by faculty to improve the effectiveness of the course and teaching skills.
\end{abstract}

\section{KEYWORDS}

Academic, Apriori, Asp.Net, Feedback, Knowledge, Mining, Php

\section{INTRODUCTION}

With competitive environment prevailing among the educational institutions, the main objective of higher education institutes is to disseminate quality education to its students and to improve the quality of managerial decisions. Quality of education can be improved by gaining knowledge from educational data which facilitate academic planners in higher education institutes to enhance their decision making process, to improve students' academic performance and better understand students' behavior, to assist instructors, to improve teaching and many other benefits and for achieving this data mining plays an important role. Data Mining is the process of applying intelligent methods to extract data patterns. It is a powerful analytical tool that enables educational institutions to better allocate resources and staff, manage student feedback [1].Applying data mining techniques to educational data for knowledge discovery is significant to educational organizations as well as students. Educational data mining is an emerging trend, concerned with developing techniques for exploring, and analyzing the huge data that come from the educational context and using those methods to better understand student interests [2][3]. EDM consists of Web-based data mining software tools which helps in managing knowledge to 
gain competitive advantage, information dissemination and knowledge acquisition, analytic capabilities and enhances our understanding of learning process to focus on identifying, extracting and evaluating variables related to the learning process of students[4].The key advantages of these web-based tools is that they are helpful in future analysis, decision-making and feedback based on dynamic data[5].These web-based data mining tools provide management of the institution with information to improve educational trends. The Web-based applications and data-mining environments are becoming important media for collecting, sharing and distributing information [6].There are learning content management system platforms which facilitate information sharing and communication between participants in a course where massive online courses are provided to students where they can opt courses accordingly, give online tests, prepare assignments, engage in discussions, chats etc [7].

\section{Classification USING Web BaSed TOOLS}

One of the most useful data mining techniques for e-learning is classification. Classification is the processing of finding a set of models which describe and distinguish data classes or concepts. The derived model may be represented in various forms, such as classification (IF-THEN) rules, decision trees, mathematical formulae, or neural networks [8]. We implemented feedback system developed in Php and Apriori application in Asp.Net taking sample of student's data. Using Association Rule Mining, we find association rules with support and confidence for optional and elective courses mostly opted by students. These methods have been applied to web-based educational systems where associations discovered shows which contents students tend to access together, or which combination of subjects they want to opt.

\subsection{Web enabled educational ARM tool}

In data mining, association rule learning is a method where interesting relations are discovered between variables in large databases [9] and ARM task is to find hidden association relationship between the different item sets in transaction database [10].

Web enabled Association Rule Mining tool proposed in this paper has used an SQL query mechanism for querying the discovered knowledge in the form of association rules.ARM techniques are applied to databases of transactions where each transaction consists of a set of items[11]. The suggested web-based tool, developed using ASP.NET framework, can be helpful for universities or institutions providing the students with elective courses. It can be utilized to:

- Generate the combinations of elective courses most opted on the basis of feedback of students.

- Generate the combinations of elective courses best recommended on the basis of feedback from industry experts.

Then so formed combinations can be adopted by university/institution to provide students with courses which are considered to be both interesting and beneficial. 
International Journal of Data Mining \& Knowledge Management Process (IJDKP) Vol.5, No.6, November 2015

\subsubsection{Framework:}

- Data Selection

The data is input from the students using a web-form shown in Fig.1

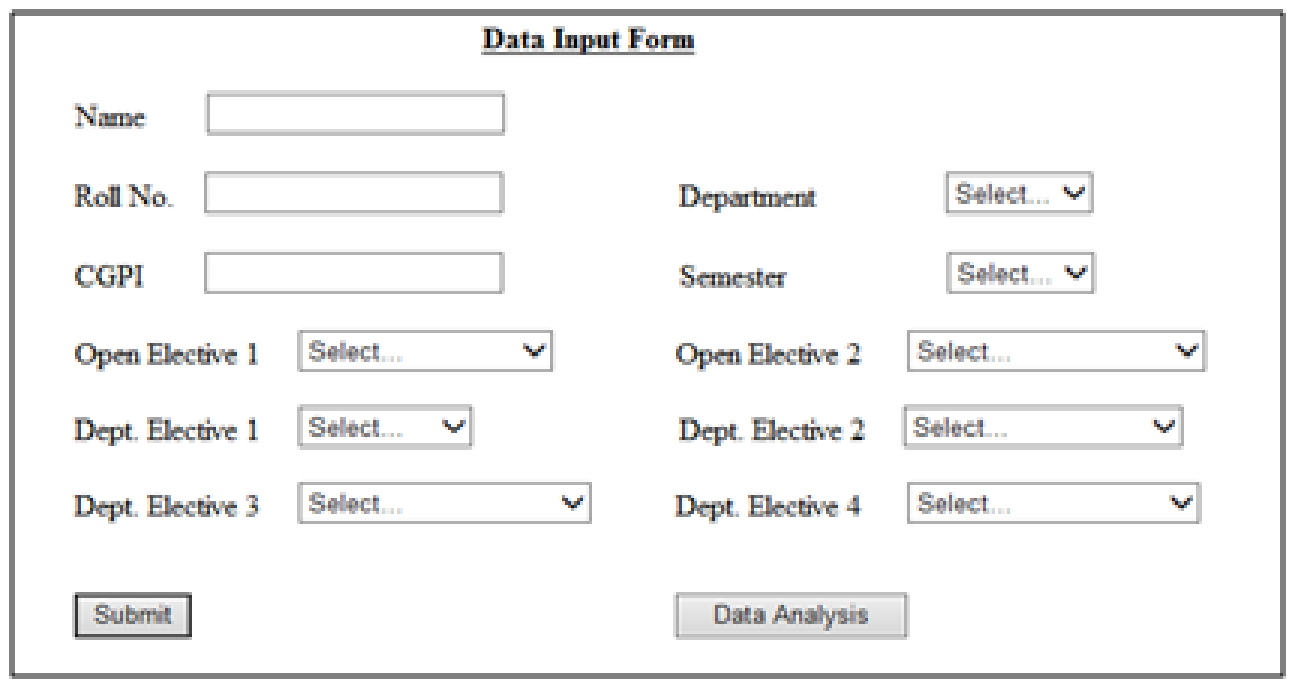

Fig 1.Input Form for students to select Open Elective and Department Elective Courses.

- Database Structure:

The structure of the database being used to store transactions and derive association rules is shown in Fig.2.

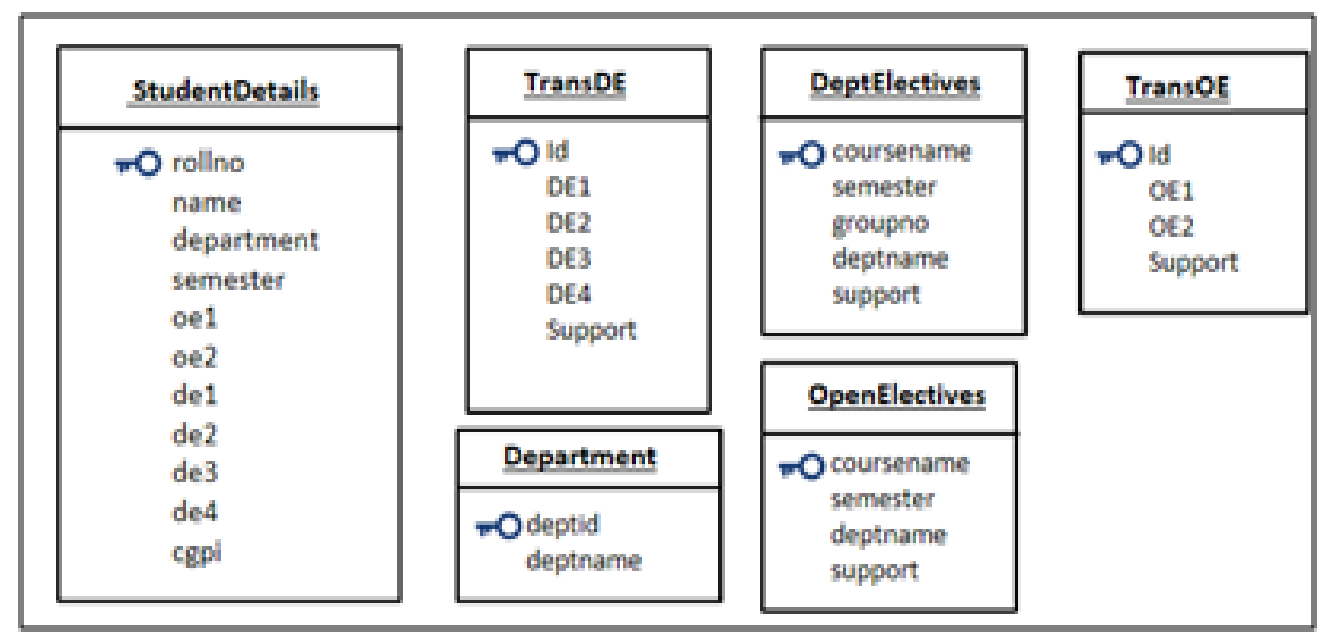

Fig 2. Design of database structure

- Purpose of Tables:

Tables used in this tool along with their description are shown in Table 1. 
Table 1: Description of tables used in ARM tool

\begin{tabular}{|l|l|}
\hline \multicolumn{1}{|c|}{ Table Name } & \multicolumn{1}{c|}{ Description } \\
\hline Student Details & To store information regarding the students. \\
\hline DeptElectives & $\begin{array}{l}\text { It contains the list of all departmental electives being offered to the } \\
\text { students. }\end{array}$ \\
\hline OpenElectives & $\begin{array}{l}\text { It contains the list of all open electives being offered to the } \\
\text { students. }\end{array}$ \\
\hline Departments & It contains list of all the departments. \\
\hline TransOE & $\begin{array}{l}\text { It contains all the transactions of open electives which are to be } \\
\text { analyzed. }\end{array}$ \\
\hline TransDE & $\begin{array}{l}\text { It contains all the transactions of departmental electives which are } \\
\text { to be analyzed. }\end{array}$ \\
\hline
\end{tabular}

\section{- Sample dataset:}

Sample Dataset containing transactions for implementing Association Rule Mining is shown in Table 2. For generating Association Rules of the data collected, user is prompted to enter the input parameters i.e. Support value and Confidence percentage. Using ARM [12], rules are selected only if they satisfy both a minimum support and a minimum confidence threshold. The sample input parameters shows support $=2$ and confidence $=40 \%$ in Fig. 3 .

Table 2: Sample Dataset showing subjects taken as open elective and departmental elective

\begin{tabular}{|c|c|c|c|c|c|}
\hline $\begin{array}{c}\text { Open } \\
\text { Elective1 }\end{array}$ & $\begin{array}{c}\text { Open Elective } \\
2 \\
\end{array}$ & $\begin{array}{c}\text { Deptt } \\
\text { Elective } 1\end{array}$ & $\begin{array}{c}\text { Deptt } \\
\text { Elective } 2\end{array}$ & Deptt Elective 3 & Deptt Elective 4 \\
\hline $\begin{array}{c}\text { Digital } \\
\text { Electronics }\end{array}$ & Communication & $\begin{array}{c}\text { Artificial } \\
\text { Intelligence }\end{array}$ & $\begin{array}{c}\text { Mobile } \\
\text { DB }\end{array}$ & Adv.Microprocessor & Embedded Systems \\
\hline IBE & Industrial Env. & Web Tech. & $\begin{array}{l}\text { Distributed } \\
\text { Systems }\end{array}$ & $\begin{array}{c}\text { Adv. } \\
\text { Microprocessor }\end{array}$ & Embedded Systems \\
\hline IBE & Industrial Env. & Web Tech. & $\begin{array}{l}\text { Distributed } \\
\text { Systems }\end{array}$ & Parallel Algo. & Adv.Comp.Networls \\
\hline IBE & Nuclear Phy. & $\begin{array}{c}\text { Artificial } \\
\text { Intelligence }\end{array}$ & $\begin{array}{c}\text { Mobile } \\
\text { DB }\end{array}$ & Parallel Algo. & Adv.Comp.Network \\
\hline $\begin{array}{c}\text { Digital } \\
\text { Electronics }\end{array}$ & $\begin{array}{l}\text { Computer } \\
\text { Graphics }\end{array}$ & $\begin{array}{c}\text { Artificial } \\
\text { Intelligence }\end{array}$ & $\begin{array}{l}\text { Distributed } \\
\text { Systems }\end{array}$ & Adv.Microprocessor & Embedded Systems \\
\hline Robotics_1 & $\begin{array}{c}\text { Neural } \\
\text { Networks }\end{array}$ & $\begin{array}{c}\text { Artificial } \\
\text { Intelligence }\end{array}$ & $\begin{array}{l}\text { Distributed } \\
\text { Systems }\end{array}$ & Adv.Microprocessor & Embedded Systems \\
\hline Optimization & Nuclear Phy. & Web Tech. & $\begin{array}{c}\text { Mobile } \\
\text { DB }\end{array}$ & Parallel Algo. & Adv.Comp.Network \\
\hline RDBMS & Robotics_2 & Web Tech & $\begin{array}{l}\text { Distributed } \\
\text { Systems }\end{array}$ & Parallel Algo & Adv.Comp.Network \\
\hline ---------- & 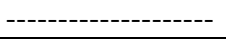 & ------------------- & ------------- & 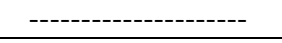 & 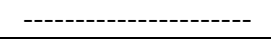 \\
\hline
\end{tabular}

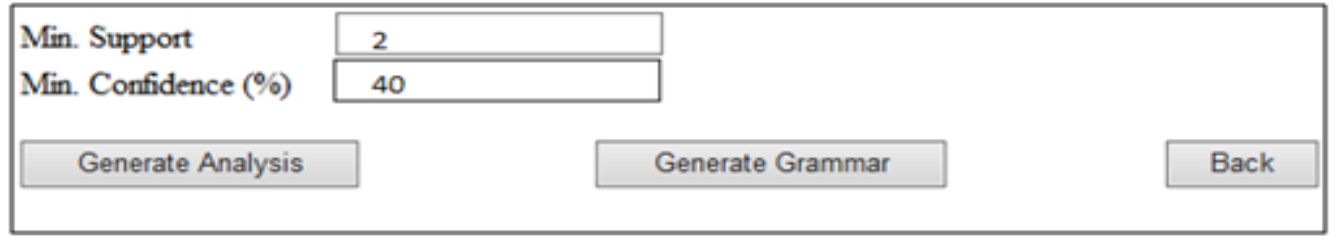

Fig.3 Support and Confidence are input parameters where threshold values assumed for Min Support is 2 and Confidence is $40 \%$. 


\section{WEB BASED FEEDBACK ANALYSIS TOOL}

Web Based Feedback Analysis tool proposed in this paper developed using php for collecting feedback of faculty and institutional infrastructure from students and that information is helpful in decision-making for Management.

\subsubsection{System Framework}

- Data Source:

Tool suggested in this paper has focused on understanding the various issues related to successful implementation of teaching practices and Institutional infrastructure after acquiring knowledge from student's feedback analytical tool. Feedback collected from students is taken as sample for this study. Students give feedback in the form of rating i.e. 110 and attributes used in database are shown in Table 3 and Table 4.

- Pre-Processing:

It consists of filtering and formatting of data. In this tool, constraint based approach is followed for students while filling the feedback form like students can directly select the faculty name from the Dropdown list boxes so as to avoid any missing or false entries. It not helps in proper evaluation of results as well reduce the time consumption. For doing classification, Table 5 shows the features on basis of which students have to rate faculty members and Institution in our Feedback Analytical System and Fig.4 and 5 shows the User Interface for giving the feedback for faculty and institution.

Table 3: Attributes for faculty

\begin{tabular}{|l|l|}
\hline Fieldname & Data type \\
\hline ID & int \\
\hline Name & varchar(30) \\
\hline Knowledge & int \\
\hline Comm. & int \\
\hline Response & int \\
\hline Uniformity & int \\
\hline Exercises & int \\
\hline Cooperation & int \\
\hline Adherence & int \\
\hline
\end{tabular}

Table 4: Attributes for Institute

\begin{tabular}{|l|l|}
\hline Fieldname & Data type \\
\hline Id & int \\
\hline Contents & int \\
\hline Planning & int \\
\hline Material & int \\
\hline Library & int \\
\hline Infra & int \\
\hline cleanliness & int \\
\hline
\end{tabular}

Table 5: Classification of features on basis of which students will rate faculty and institution

\begin{tabular}{|c|l|l|}
\hline SrNo. & Features for Faculty Rating & Features For Institutional Rating \\
\hline 1 & Knowledge & Course Contents \\
\hline 2 & Communication and Presentation & Planning of Programme(Course calendar) \\
\hline 3 & Response to Queries & Course Material \\
\hline 4 & Uniformity in Evaluation & Library Facility \\
\hline 5 & Class Room Exercise & Infrastructure(Class Rooms, Practical Labs) \\
\hline 6 & Cooperation with students & Cleanliness \\
\hline 7 & Adherence to schedule & General Arrangement of work Place \\
\hline
\end{tabular}


International Journal of Data Mining \& Knowledge Management Process (IJDKP) Vol.5, No.6, November 2015

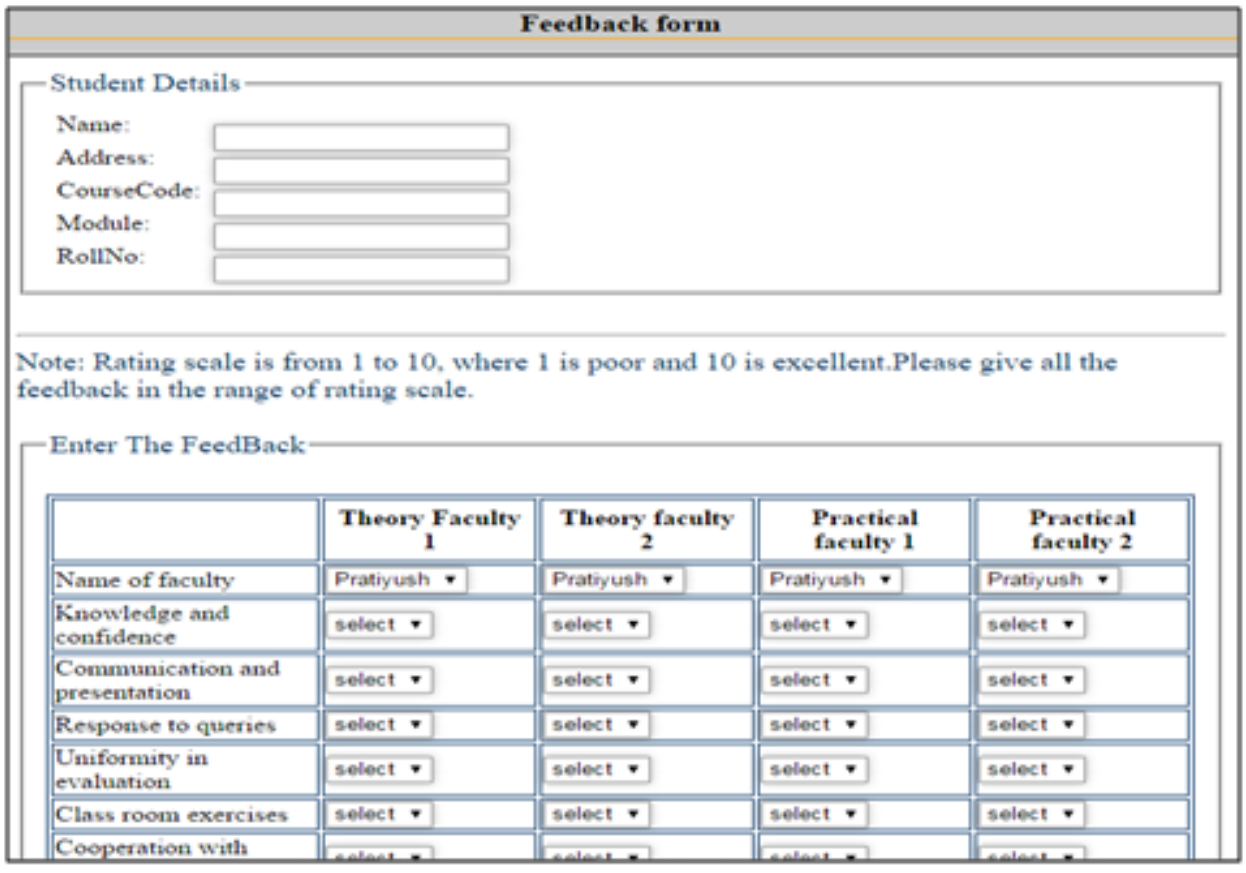

Fig.4 Faculty feedback form where students will rate faculty for theory and practical subjects

\begin{tabular}{|c|c|c|}
\hline & & Rating Scale(1-10) \\
\hline 1. & Course contents & \\
\hline 2. & $\begin{array}{l}\text { Planning of Programme(Course } \\
\text { Calender) }\end{array}$ & \\
\hline 3. & Course Material & \\
\hline 4. & Library facility & \\
\hline 5. & $\begin{array}{l}\text { Infrastructure(Class } \\
\text { Rooms.Practical Labs etc.) }\end{array}$ & \\
\hline 6. & $\begin{array}{l}\text { Cleanliness \& Gen arrangement of } \\
\text { work place }\end{array}$ & \\
\hline
\end{tabular}

Fig.5 Infrastructure feedback form where rating is done to analyze institution performance

- Pattern Discovery

Feedback is collected from students in the form of database and query mechanism is applied on it and results derived in Fig. 8 and 9 shows overall performance of Faculty members and improvements required in institutional infrastructure. 


\section{RESULTS AND DISCUSSIONS}

The Association Rules generated for Open and Departmental Electives are shown in Fig. 6 and Fig.7 respectively for the input parameter values supplied in Fig.3.From Fig 6 and 7, we derive that Association Rules for Departmental Elective shows that students who have opted for Web Technologies have also opted for Distributed Systems and with Distributed Systems, Advanced Microprocessor combinations are there. Frequent Item sets shown in Fig 6 shows some open elective courses and support for them. The maximum support is for "Digital Electronics", "IBE" i.e. Open Elective 1, "CPM_2", "Neural Networks" i.e. Open Elective 2 and strong rules shown in Fig 6 for OE are Digital Electronics $=>C P M \_2$ and CPM_1=>CG.Similarly, Frequent Item sets shown in Fig 7 shows Departmental Elective Courses and support for them. Maximum Support is 7 for Artificial Intelligence i.e. Departmental Elective 1, Mobile DB i.e. Department Elective 2, Parallel Algorithm i.e. Department Elective 3 and Adv.Computer Networks i.e. Department Elective 4.

A result using Feedback Analytical Tool in Fig 8 and 9 shows the rating for faculty members and institute given by students based on attributes shown in Table 3 and Table 4.

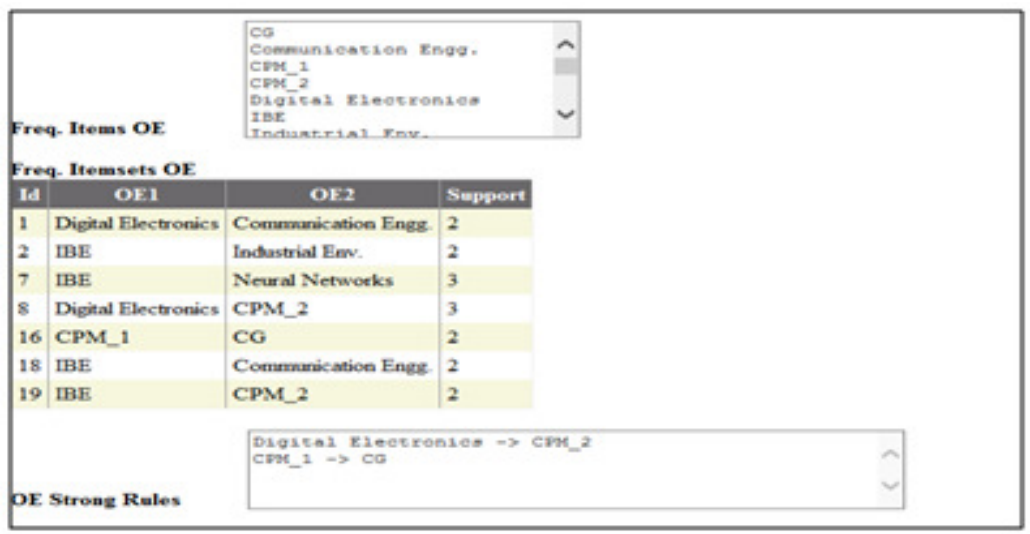

Fig.6 Association rules generated by application for open elective subjects

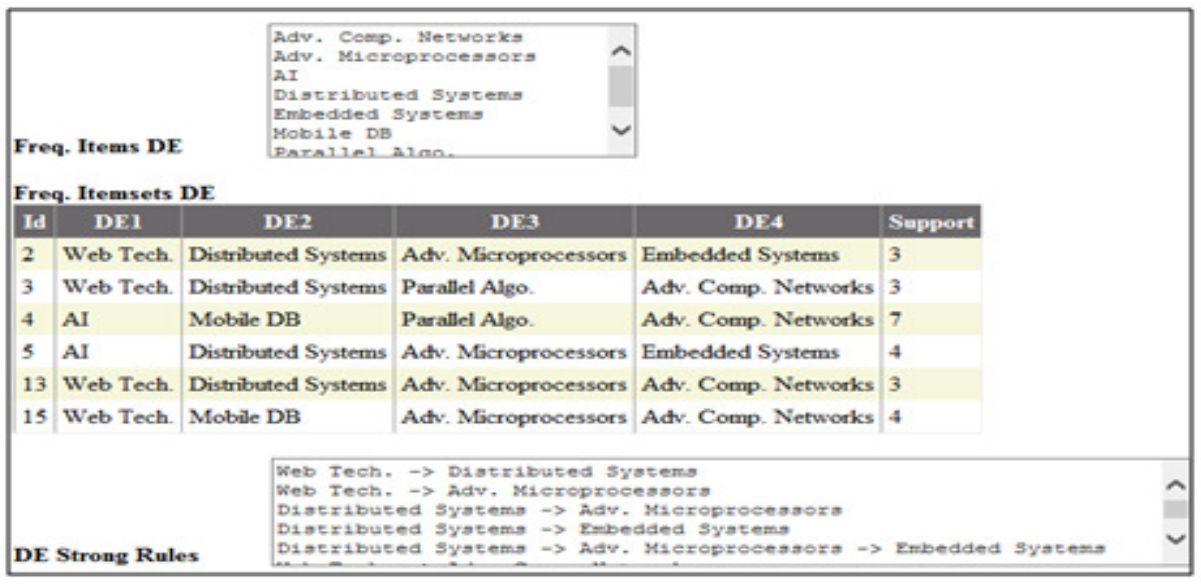

Fig.7 Association rules generated by application for department elective subjects 


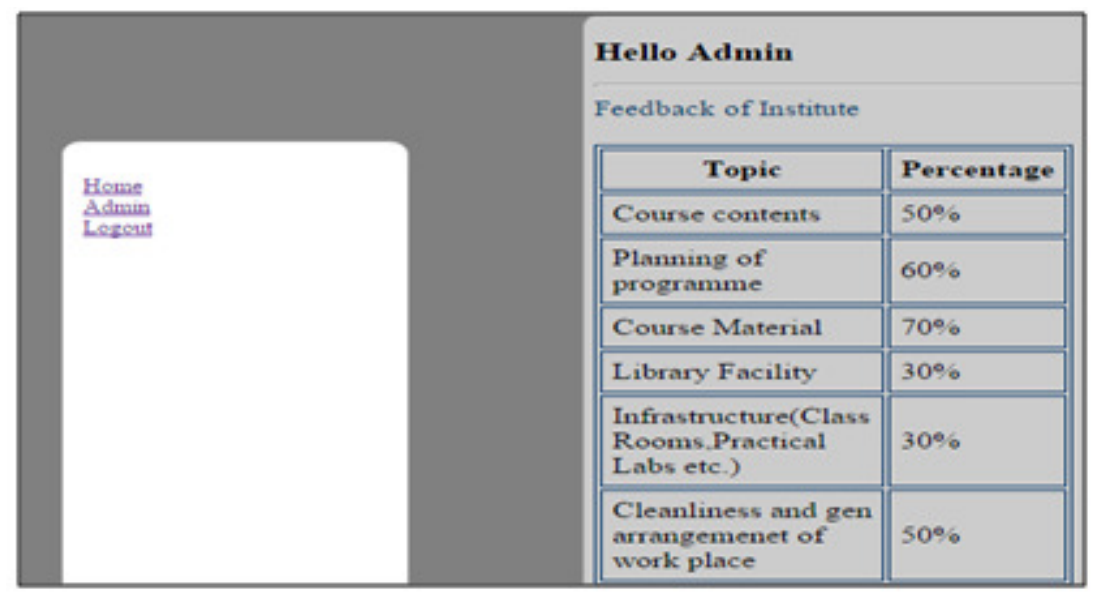

Fig.8 Feedback of institute generated by PHP based application

Fig 8 and 9 shows Feedback Analysis of Institute and Faculty taking Theory and Practical Classes. Results shown not only helps in Faculty Development but also results in improvement of Institutional Infrastructure needs, course curriculum and decision making.

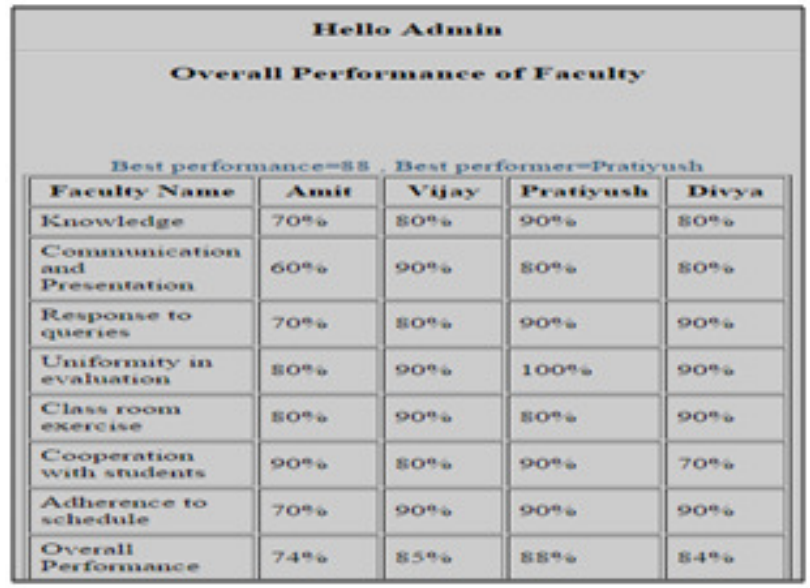

Fig.9 Faculty performance results generated by application for theory and practical subjects

\section{CONCLUSION}

With the growth in Web-based applications which includes massive open online courses,elearning,there is significant increase in analyzing educational trends through web-based tools and apply that knowledge to better serve users,students.Web-Based Data mining tools have shown significant results in educational sector, in-depth analysis of data and results generated. Tools proposed in this paper have targeted educational sector and students. It not helps in quality assurance but also leads to effective knowledge management. Web-based data mining tools provide the skill to understand and infer the generated information, managing knowledge which is the source of competitive advantage. We have taken care of simplicity in graphical user interfaces of tools so that students don't face any problems while filling the input data forms. ARM Tool proposed for Classification of Association rules helps the educators, management in 
International Journal of Data Mining \& Knowledge Management Process (IJDKP) Vol.5, No.6, November 2015

knowledge discovery and students interest towards technologies, composing and recommending new courses. Using these tools, we concluded that visualization results generated are intuitive, meaningful to educators, management for effective decision-making and can be useful in predicting student outcomes. Further in this direction we are working to integrate feedback and results obtained with data mining directly applied to the e-learning environment.

\section{REFERENCES}

[1] Luan Jing (2001). Data Mining Applications in Higher Education. A chapter in the upcoming New Directions for Institutional Research. Josse-Bass. San Francisco

[2] Sachin R.B, Vijay M.S (2012). A Survey and Future Vision of Data Mining in Educational Field. pp.96 - 100.ISBN:978-1-4673-0471-9

[3] Goyal Monika, Vohra Rajan (2012).Applications of Data Mining in Higher Education. IJCSI. Vol. 9, Issue 2, No 1. ISSN (Online): 1694-0814

[4] Bhardwaj Brijesh Kumar, Pal Saurabh (2011) Mining Educational Data to Analyze Students Performance. International Journal of Advanced Computer Science and Applications. Vol. 2, No. 6.

[5] Heinrichs H. John, Lim Su-Jeen (2003). Integrating web-based data mining tools with business models for knowledge management. Decision Support Systems 35,103- 112.

[6] Zaiane O. R., Luo J. (2001). Towards evaluating learners' behaviour in a web-based distance learning environment. In Advanced Learning Technologies, 2001. Proceedings. IEEE International Conference on (pp. 357-360). IEEE.

[7] Romero C, Ventura S. (2007) Educational data mining: A survey from 1995 to 2005.Expert Systems with Applications 33, 135-146

[8] Sarma Deva Kumar Pankaj, Roy Rahul (2010) A Data Warehouse for Mining Usage Pattern in Library Transaction Data. Assam University Journal of Science \&Technology: Physical Sciences and Technology Vol. 6 Number II, 125-129.

[9] Ruijuan Hu (2010). Medical Data Mining Based on Association Rules. Computer and Information Science, ISSN 1913-8989 E-ISSN 1913- 8997, Vol. 3, No. 4.

[10] Liu B. and Wong C.K. (2000).Improving an association rule based classifier. Journal in Principles of Data Mining and Knowledge Discovery, p. 504-509

[11] Cooley R., Mobasher B., Srivastava J. (1997) Web Mining: Information and Pattern Discovery on the World Wide Web. DOI: 10.1109/TAI.1997.632303 • Source: IEEE Xplore.

[12] Goh, Dion. H., Ang Rebecca P. (2007). An introduction to association rules mining: An application in counseling and help-seeking behavior of adolescents. Behavior Research Methods, 39 (2), 259-266.

\section{AUTHORS}

Pratiyush Guleria has done Mtech in Computer Science with a Gold Medal from Himachal Pradesh University, Shimla, INDIA. He has received his MBA in Operation Research from Indira Gandhi National Open University (IGNOU) and Btech in Information Technology from I.E.E.T Baddi, Distt Solan, Himachal Pradesh University. He has more than 6 Years of Experience in IT Industry and Academics. His research interests include Data Mining and Web Technologies.

Akshay Sharma is pursuing his Btech in Computer Science from National Institute of Technology, Hamirpur.His research interests include Data Mining, Web Technologies.
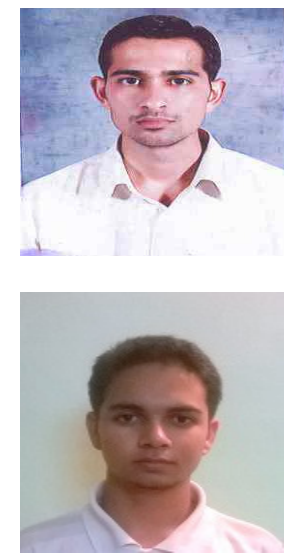
International Journal of Data Mining \& Knowledge Management Process (IJDKP) Vol.5, No.6, November 2015

Prof. Manu Sood is currently working as a Professor in the Department of Computer Science at Himachal Pradesh University Shimla, India. He has completed his Ph.D. in Computer Engineering under the Faculty of Technology from University of Delhi, Delhi, India. He completed his M. Tech. in Information Systems with a Gold Medal from Netaji Subhash Institute of Technology, Delhi, India. He has received his B.E. degree in Electronics and Telecommunication from Government Engineering College, Jabalpur, Madhya Pradesh, India. Prof. Sood has over 25 years of extensive experience in IT Industry and Academics in India at various positions. His research interests include Software Engineering, Model Driven Software Development, Model Driven Architecture, Aspect Oriented Software Development, E-learning, Service Oriented Architecture, MANETs and VANETs. 